\title{
BMJ Open Gender differences in health-related quality of life associated with abdominal obesity in a Korean population
}

\author{
Jina Choo, ${ }^{1}$ Seonhui Jeon, ${ }^{2}$ Juneyoung Lee ${ }^{3}$
}

To cite: Choo J, Jeon S, Lee J. Gender differences in health-related quality of life associated with abdominal obesity in a Korean population. BMJ Open 2014:4:e003954. doi:10.1136/bmjopen-2013003954

- Prepublication history and additional material for this paper is available online. To view these files please visit the journal online (http://dx.doi.org/10.1136/ bmjopen-2013-003954)

Received 4 September 2013 Revised 20 November 2013 Accepted 10 December 2013

CrossMark

For numbered affiliations see end of article.

Correspondence to Dr Juneyoung Lee; jyleeuf@korea.ac.kr

\section{ABSTRACT}

Objectives: Overall obesity, as measured by body mass index (BMI), has been associated with a low level of health-related quality of life (HRQOL), but little is known about abdominal obesity. This cross-sectional study aimed to determine whether abdominal obesity, as measured by waist circumference (WC), would be significantly associated with HRQOL independent of overall obesity, and if so, whether the association would differ by gender among the Korean population.

Design: Cross-sectional study.

Setting: South Korea.

Participants: Using data from the 2007-2009 Korea National Health and Nutrition Examination Survey, a total of 13754 men and women aged 19-65 years were selected, and information about height $(\mathrm{cm})$, weight $(\mathrm{kg})$, WC $(\mathrm{cm})$ and the EuroQOL-5 Dimensions (EQ-5D) scores for HRQOL were taken.

Results: Not only an overall obesity (as categorised into obese, overweight or non-overweight groups based on BMI) but also an abdominal obesity (defined by $W C \geq 90 \mathrm{~cm}$ for men and $\geq 85 \mathrm{~cm}$ for women) was significantly associated with lower EQ-5D scores, after adjusting for age, gender, socioeconomic variables and a number of comorbidities. Even after adjusting BMI effect, the association between abdominal obesity and lower EQ-5D scores remained significant for women, but not for men.

Conclusions: Among the Korean population aged 19-65 years, abdominal obesity was associated with impaired HRQOL, independently of overall obesity. Furthermore, this association differed by gender, being significant only for women. Therefore, primary healthcare professionals should pay attention to gender differences in the impact of obesity on HRQOL when evaluating population-based health programmes.

\section{INTRODUCTION}

Obesity is a major public health concern, and its prevalence is currently on the rise not only in low-income and middle-income countries but also in high-income countries. The WHO has estimated that one billion people are overweight and more than 300 million

\section{Strengths and limitations of this study}

- The first study reporting a significant association between abdominal obesity and health-related quality of life (HRQOL) in the general population, with the adjustment for all the potential confounding factors.

- Our study results may not guarantee a causal relationship between abdominal obesity and $\mathrm{HRQOL}$, due to the nature of a cross-sectional study design, and also might not be generalisable to other cultural population groups.

- More attention should be given to the modifying effects of gender when analyzing the impacts of abdominal obesity on HRQOL.

are obese worldwide, based on the criteria for an overall obesity as measured by body mass index (BMI). ${ }^{1}$ In South Korea, $26 \%$ of adults aged 19 years and over were overweight or obese in 1998, specifically $25.1 \%$ for men and $26.2 \%$ for women. By 2009 , this figure had risen to $31.3 \%$, specifically $35.8 \%$ of men and $26 \%$ of women. ${ }^{2}$

Overall obesity as measured by BMI is a wellestablished risk factor for coronary heart disease and type II diabetes mellitus. ${ }^{3}{ }^{4}$ Furthermore, overall obesity is linked to impaired health-related quality of life (HRQOL). Several previous studies have reported that individuals who were overweight and obese showed significantly lower levels of HRQOL than those with normal weight in the general population of Western countries, including the US, the UK, German and Spanish populations. ${ }^{5-8}$ However, few studies have reported an association between overall obesity and HRQOL in Asian populations, even among Koreans. ${ }^{9}$

Abdominal obesity has received attention for its multiple health outcomes. The Nurses' Health Study reported that abdominal obesity, as measured by waist circumference (WC), was independently associated with the risk for coronary heart disease and 
cancer in women. ${ }^{10}{ }^{11} \mathrm{~A}$ meta-analysis showed that, for a $1 \mathrm{~cm}$ increment in WC, the relative risk of cardiovascular events increased by $2 \% .^{12}$ Nonetheless, abdominal obesity has not yet been studied in predicting HRQOL, beyond overall obesity, among the general population.

The impact of obesity may vary by gender. Significantly a higher number of women considered themselves as overweight than did men, and also reported experiencing discomfort due to excessive weight, than did men. ${ }^{13} 14$ This implies that gender may be one of the significant factors that could modify an association of obesity with HRQOL. However, it has rarely been considered in the epidemiological literature on the study of obesity and HRQOL in the general population. A few studies have reported that obesity had a much greater impact on HRQOL impairment and mortality for obese women relative to obese men among Americans. ${ }^{15}$ However, such a gender difference may differ by population groups with diverse sociocultural contexts. Although fatness was valued traditionally for being associated with prosperity and good health in Korea before the 1980s, thinness has recently become to be valued with the rapid economic growth over the past several decades, especially among women.

In this respect, this study aimed to determine whether abdominal obesity and overall obesity would be significantly associated with HRQOL, as measured by the EuroQOL-5 Dimensions (EQ-5D), after adjusting for potential confounding factors. We then examined whether the association of abdominal obesity with HRQOL would remain significant even after controlling for an effect of overall obesity. We also evaluated whether gender differences existed in the association between abdominal obesity and HRQOL. To investigate these, we utilised nationally representative Korean population data from the fourth round of the Korea National Health and Nutrition Examination Survey (KNHANES IV) conducted in 2007-2009.

\section{METHODS}

\section{Design and study population}

A cross-sectional design was used in the present study. The KNHANES is a cross-sectional and nationally representative study using a multistage stratified cluster sampling for the selection of household units among non-institutionalised civilians in Korea, which has been conducted by the Korea Centers for Disease Control and Prevention. The KNHANES IV was conducted over 3 years 2007-2009 using three rolling sampling surveys. ${ }^{16}$ Owing to these sampling characteristics, findings obtained from the 2007-2009 data in the KNHANES IV should be interpreted as multi-year average estimates. ${ }^{16} 17$ The survey consisted of a Health Interview Survey, Health Examination and Nutrition Survey.

The total number of participants in the KNHANES IV was 24 437, who were recruited across all life stages from infancy to old age. ${ }^{16}$ Of the KNHANES IV data, our study used 13754 participants aged 19-65 years. We did not include the elderly population group because they were not considered as part of the post World War II birth cohort who adapted to westernised lifestyles and manifested obesity-related health conditions. ${ }^{18}$

\section{Measures}

Our measure of HRQOL is the EQ-5D, ${ }^{19}{ }^{20}$ which is a generic measure of HRQOL considering five dimensions, namely mobility, self-care, usual activities, pain/discomfort and anxiety/depression. Each dimension is scored at 1 of 3 levels, depending on whether the respondent has no problems $($ score $=1)$, some problems $($ score $=2$ ) or serious problems $($ score $=3$ ) with each of the dimensions. The EQ-5D score at each dimension was converted to a single summary index by applying a formula that attaches weights to each of the levels in each dimension. A number of such formulas, or value sets, are available for different countries, based on the valuation of the EQ-5D from general population samples. The KNHANES uses weights obtained from the Korean population by the Korea Centers for Disease Control and Prevention. ${ }^{21}$ After applying these weights, an EQ-5D index score represents the status of health, with a score of zero being equivalent to death, negative scores representing health states worse than death and a maximum score of $1 .^{20}$

Our obesity measures are BMI and WC. BMI was calculated by weight in kilograms divided by height in metres squared $\left(\mathrm{kg} / \mathrm{m}^{2}\right)$. Overall obesity was classified into three categories according to the BMI categories defined by the $\mathrm{WHO}^{22}$ : non-overweight, $\mathrm{BMI}<25$; overweight, BMI 25-29.9 and obese, BMI $\geq 30 \mathrm{~kg} / \mathrm{m}^{2}$. WC was measured in centimetres $(\mathrm{cm})$ at the end of normal expiration and to the nearest $0.1 \mathrm{~cm}$, measuring at the midpoint between the lower borders of the rib cage and the iliac crest with a measuring tape (Seca, Germany). Abdominal obesity was determined as WC of $90 \mathrm{~cm}$ or greater for men and $85 \mathrm{~cm}$ or greater for women, according to the criterion for abdominal obesity as defined by the Korean Society for the Study of Obesity. ${ }^{23}$ Each measurement was taken by trained nurses during the KNHANES IV health examination survey.

The following sociodemographic and health-related variables were obtained from the KNHANES IV database: age, household income (highest, middle-high, middle-low and low levels), education $(\leq 6,7-9,10-12$ and $\geq 13$ years), employment (yes, no), marital status (married, separated/widowed/divorced and never married), smoking status (current-smokers, ex-smokers and non-smokers) and numbers of comorbidities. The comorbidities used in this study were defined as disease status diagnosed by physicians, consisting of coronary heart disease, stroke, diabetes mellitus, asthma, chronic obstructive pulmonary disease, renal failure and cancers.

\section{Ethical consideration}

All participants in the survey provided their informed consent. This study was conducted in accordance with the declaration of Helsinki. 


\section{Data analysis}

All data analyses were conducted using SAS statistical software, V.9.2 (SAS Institute Inc, Cary, North Carolina, USA). The demographic characteristics of the study participants were expressed as either means (SE) or numbers and prevalence (SE), as appropriate, for total participants as well as for men and women. The survey weights were taken into account to obtain the SEs of prevalence. Gender differences for all participants' demographic, socioeconomic and anthropometric characteristics as well as for EQ-5D scores were analysed with Student t test or $\chi^{2}$ test, as appropriate, using the SURVEYMEANS or SURVEYFREQ procedures in SAS to reflect the study weights, respectively. A multivariable analysis for gender differences for EQ-5D scores, adjusting for obesity measures and other demographic and socioeconomic variables, was performed using multiple linear regression models. Two models with and without an interaction effect between gender and BMI categories of obese, overweight and non-overweight (models I and II), including each of these main effects, were examined. For the differential effect of abdominal obesity on EQ-5D scores by gender, three modelsmodel I for gender and WC main effects only, model II for gender, WC and BMI main effects and model III for an interaction effect of gender and WC along with those main effects-were examined. Common variables adjusted in the models were age, education level, income level, employment status, marital status and a number of comorbidities. For these regression analyses, the SURVEYREG procedure in SAS was used. All reported $\mathrm{p}$ values are two-tailed, and $\mathrm{p}<0.05$ was considered to be statistically significant.

\section{RESULTS}

\section{Participants' characteristics}

The demographic, socioeconomic and anthropometric characteristics of the adult population of the KNHANES IV $(\mathrm{N}=13754)$ are summarised in tables 1 and 2. The total sample had a mean age of 40.4 years, with more women $(n=7832)$ than men $(n=5922$; table 1$)$. Women comprised a lower proportion of the population who were at the highest and middle-high levels of household income $\quad(p=0.005)$, highly educated $(p<0.001)$, employed $(p<0.001)$ and never married $(p<0.001)$ than men. Of the total, $9.3 \%$ had one or more comorbidities, but there was no significant difference by gender.

Table 1 Participants' demographic and socioeconomic characteristics $(\mathrm{N}=13754)$

\begin{tabular}{|c|c|c|c|c|c|c|c|c|c|c|}
\hline & \multicolumn{3}{|c|}{ Total $(\mathrm{N}=13 \mathrm{754})$} & \multicolumn{3}{|c|}{ Men $(n=5922)$} & \multicolumn{3}{|c|}{ Women $(n=7832)$} & \multirow[b]{2}{*}{ p Value* } \\
\hline & $\overline{\mathbf{N}}$ & Per cent & (SE) & $\bar{n}$ & Per cent & (SE) & $\overline{\mathbf{n}}$ & Per cent & (SE) & \\
\hline Survey year & & & & & & & & & & 0.867 \\
\hline 2007 & 2367 & 19.8 & $(2.0)$ & 986 & 19.7 & $(2.0)$ & 1381 & 20.0 & $(2.0)$ & \\
\hline 2008 & 5426 & 40.0 & $(2.5)$ & 2323 & 40.0 & $(2.5)$ & 3103 & 40.0 & $(2.5)$ & \\
\hline 2009 & 5961 & 40.1 & $(2.5)$ & 2613 & 40.3 & $(2.5)$ & 3348 & 40.0 & $(2.5)$ & \\
\hline Age (years), mean (SE) & 13754 & 40.4 & $(0.18)$ & 5922 & 40.2 & $(0.22)$ & 7832 & 40.7 & $(0.20)$ & 0.074 \\
\hline Household income & & & & & & & & & & 0.005 \\
\hline Highest & 4243 & 32.7 & $(1.0)$ & 1902 & 33.8 & $(1.1)$ & 2341 & 31.6 & $(1.0)$ & \\
\hline Middle-high & 4089 & 30.9 & $(0.7)$ & 1791 & 31.2 & $(0.8)$ & 2298 & 30.6 & $(0.8)$ & \\
\hline Middle-low & 3412 & 25.2 & $(0.7)$ & 1420 & 24.3 & $(0.8)$ & 1992 & 26.1 & $(0.8)$ & \\
\hline Low & 1699 & 11.2 & $(0.5)$ & 676 & 10.7 & $(0.6)$ & 1023 & 11.6 & $(0.6)$ & \\
\hline Education (years) & & & & & & & & & & $<0.001$ \\
\hline$\leq 6$ & 2270 & 12.4 & $(0.4)$ & 689 & 8.8 & $(0.4)$ & 1581 & 16.1 & $(0.5)$ & \\
\hline $7-9$ & 1584 & 10.4 & $(0.4)$ & 670 & 9.7 & $(0.5)$ & 914 & 11.1 & $(0.4)$ & \\
\hline $10-12$ & 5590 & 44.3 & $(0.7)$ & 2442 & 45.0 & $(0.9)$ & 3148 & 43.5 & $(0.7)$ & \\
\hline$\geq 13$ & 4194 & 32.9 & $(0.8)$ & 2062 & 36.5 & $(0.9)$ & 2132 & 29.2 & $(0.8)$ & \\
\hline Employment & & & & & & & & & & $<0.001$ \\
\hline Yes & 8794 & 65.8 & $(0.5)$ & 4801 & 80.8 & $(0.7)$ & 3993 & 50.3 & $(0.8)$ & \\
\hline No & 4802 & 34.2 & $(0.5)$ & 1050 & 19.2 & $(0.7)$ & 3752 & 49.7 & $(0.8)$ & \\
\hline Marital status & & & & & & & & & & $<0.001$ \\
\hline Married & 10156 & 69.7 & $(0.7)$ & 4347 & 68.3 & $(1.0)$ & 5809 & 71.1 & $(0.8)$ & \\
\hline Separated/widowed/divorced & 1162 & 7.2 & $(0.3)$ & 283 & 4.3 & $(0.3)$ & 879 & 10.2 & $(0.4)$ & \\
\hline Never-married & 2341 & 23.1 & $(0.7)$ & 1241 & 27.4 & $(0.9)$ & 1100 & 18.7 & $(0.7)$ & \\
\hline Number of comorbidities & & & & & & & & & & 0.253 \\
\hline 0 & 12205 & 90.7 & $(0.3)$ & 5209 & 90.4 & $(0.5)$ & 6996 & 91.0 & $(0.4)$ & \\
\hline 1 & 1294 & 8.3 & $(0.3)$ & 578 & 8.5 & $(0.4)$ & 716 & 8.2 & $(0.4)$ & \\
\hline$\geq 2$ & 177 & 1.0 & $(0.1)$ & 96 & 1.1 & $(0.1)$ & 81 & 0.8 & $(0.1)$ & \\
\hline
\end{tabular}


A total of $69 \%$ of the participants were nonoverweight, $27 \%$ were overweight and $4.1 \%$ were obese. Women had a lower average of BMI than men $(\mathrm{p}<0.001)$, with a lower prevalence of overweight and obesity than men $(24.9 \%$ vs $37.5 \%, \mathrm{p}<0.001)$. Based on the Korean criterion of abdominal obesity, women comprised a lower proportion of the population with abdominal obesity than men $(21.1 \%$ vs $25 \%, \mathrm{p}<0.001)$.

The EQ-5D yielded a mean score of 0.958 for the total participants, with 0.946 for women versus 0.969 for men (table 2). For the five subdomains of the EQ-5D (ie, mobility, self-care, usual activities, pain/discomfort and anxiety/depression), the highest proportion of the population manifested pain/discomfort (20\%), followed by anxiety/depression, while the lowest one was problems in self-care $(1.7 \%)$. Women represented significantly greater proportions of the population manifesting any problem across all the domains of the EQ-5D than men, except for the self-care domain.

Figure 1 shows gender-specific adjusted means for EQ-5D scores according to the BMI and WC categories in the fully adjusted models with interaction terms. Overweight and obese women exhibited significantly lower EQ-5D scores compared with non-overweight women, with a decreasing trend as degree of obesity increases; however, no group is statistically different among men (figure 1A). The same patterns were observed in the WC categories despite adjusting for BMI (figure 1B).

\section{Associations between BMI categories and EQ-5D scores and gender differences}

Compared with the non-overweight individuals, the overweight individuals reported significantly lower EQ-5D scores $(\beta=-0.005, p=0.007$; model I of table 3$)$, but obese individuals did not. There was a significant interaction effect between gender and BMI categories on EQ-5D ( $\beta=$ $-0.011, p=0.002$ for women and overweight; $\beta=-0.018$, $\mathrm{p}=0.030$ for women and obese; model II of table 3). This finding indicated that overweight and obese women had significantly lower EQ-5D scores than non-overweight women, but such significance was not apparent for men (model II of table 3; see also figure 1A).

In the EQ-5D domains, the prevalence of any problem in mobility, usual activities and pain/discomfort differed significantly according to BMI category, with an increasing trend as degree of obesity increases (see online supplemental figure S1). The crude and multivariate associations between BMI category and each domain of EQ-5D by gender are shown in online supplemental tables S1 and S2. After adjusting for all the confounding variables, we found that morbidity in men and

Table 2 Participants' anthropometric characteristics and EQ-5D ( $N=13754)$

\begin{tabular}{|c|c|c|c|c|c|c|c|c|c|c|}
\hline & \multicolumn{3}{|c|}{ Total $(\mathrm{N}=13 \mathrm{754})$} & \multicolumn{3}{|c|}{ Men $(n=5922)$} & \multicolumn{3}{|c|}{ Women $(n=7832)$} & \multirow[b]{2}{*}{ p Value* } \\
\hline & $\overline{\mathbf{N}}$ & Per cent & (SE) & $\bar{n}$ & Per cent & (SE) & $\bar{n}$ & Per cent & (SE) & \\
\hline BMI, mean (SE) & 13684 & 23.60 & $(0.04)$ & 5888 & 24.16 & $(0.05)$ & 7796 & 23.03 & $(0.05)$ & $<0.001$ \\
\hline BMI categories & & & & & & & & & & $<0.001$ \\
\hline Non-overweight & 9362 & 68.7 & $(0.5)$ & 3658 & 62.5 & $(0.7)$ & 5704 & 75.1 & $(0.6)$ & \\
\hline Overweight & 3789 & 27.3 & $(0.5)$ & 2004 & 33.3 & $(0.7)$ & 1785 & 21.0 & $(0.6)$ & \\
\hline Obese & 533 & 4.1 & $(0.2)$ & 226 & 4.2 & $(0.3)$ & 307 & 3.9 & (0.3) & \\
\hline WC, mean (SE) & 13677 & 80.80 & $(0.1)$ & 5888 & 84.09 & $(0.2)$ & 7789 & 77.39 & $(0.2)$ & $<0.001$ \\
\hline WC categories & & & & & & & & & & $<0.001$ \\
\hline Normal waist & 10251 & 76.9 & $(0.5)$ & 4323 & 75.0 & $(0.7)$ & 5928 & 78.9 & $(0.6)$ & \\
\hline Abdominal obesity & 3426 & 23.1 & $(0.5)$ & 1565 & 25.0 & $(0.7)$ & 1861 & 21.1 & $(0.6)$ & \\
\hline EQ-5D, mean (SE) & 13638 & 0.958 & $(0.001)$ & 5861 & 0.969 & $(0.001)$ & 7777 & 0.946 & $(0.001)$ & $<0.001$ \\
\hline Morbidity & & & & & & & & & & $<0.001$ \\
\hline Any problem & 1395 & 8.1 & $(0.3)$ & 435 & 5.9 & $(0.3)$ & 960 & 10.4 & $(0.4)$ & \\
\hline None & 12244 & 91.9 & $(0.3)$ & 5427 & 94.1 & $(0.3)$ & 6817 & 89.6 & $(0.4)$ & \\
\hline Self-care & & & & & & & & & & 0.214 \\
\hline Any problem & 295 & 1.7 & $(0.1)$ & 118 & 1.6 & $(0.2)$ & 177 & 1.9 & $(0.2)$ & \\
\hline None & 13344 & 98.3 & $(0.1)$ & 5744 & 98.4 & $(0.2)$ & 7600 & 98.1 & $(0.2)$ & \\
\hline Usual ac & & & & & & & & & & $<0.001$ \\
\hline Any problem & 903 & 5.2 & $(0.2)$ & 301 & 4.0 & $(0.3)$ & 602 & 6.5 & $(0.3)$ & \\
\hline None & 12736 & 94.8 & $(0.2)$ & 5561 & 96.0 & $(0.3)$ & 7175 & 93.5 & $(0.3)$ & \\
\hline Pain/discomfort & & & & & & & & & & $<0.001$ \\
\hline Any problem & 3009 & 20.0 & $(0.5)$ & 976 & 15.4 & $(0.6)$ & 2033 & 24.8 & $(0.7)$ & \\
\hline None & 10629 & 80.0 & (0.5) & 4885 & 84.6 & (0.6) & 5744 & 75.2 & $(0.7)$ & \\
\hline Anxiety/depression & & & & & & & & & & $<0.001$ \\
\hline Any problem & 1691 & 11.4 & $(0.4)$ & 423 & 6.7 & $(0.4)$ & 1268 & 16.3 & $(0.6)$ & \\
\hline None & 11948 & 88.6 & $(0.4)$ & 5439 & 93.3 & $(0.4)$ & 6509 & 83.7 & $(0.6)$ & \\
\hline
\end{tabular}

*Significance levels for gender difference analysed with Student $t$ test or $\chi^{2}$ test, as appropriate, using the SURVEYMEANS or SURVEYFREQ procedures in SAS to reflect the study weights.

BMI, body mass index; EQ-5D, EuroQOL-5 Dimensions Scores; WC, waist circumference. 
A.

1.00

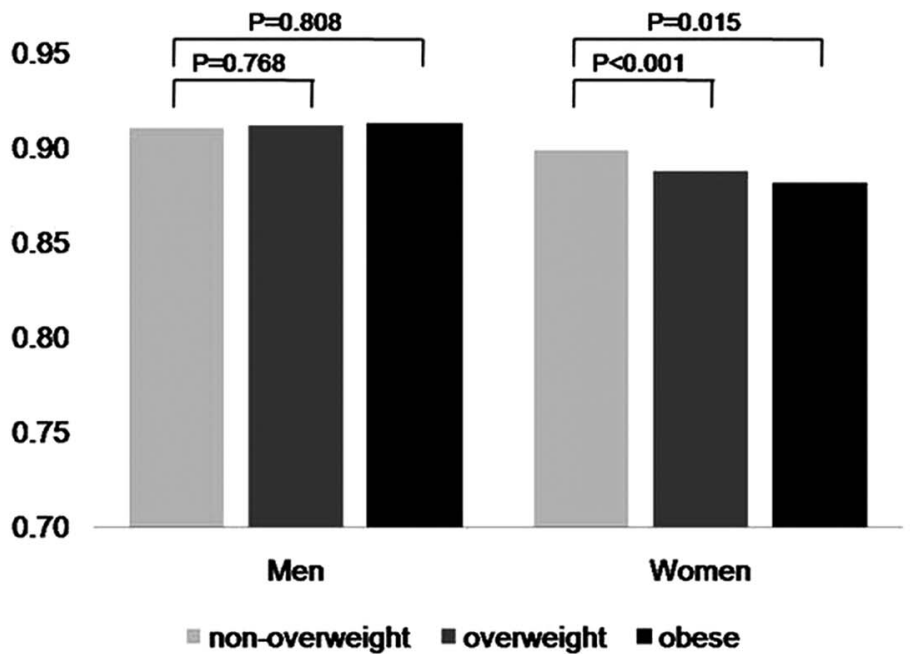

B.

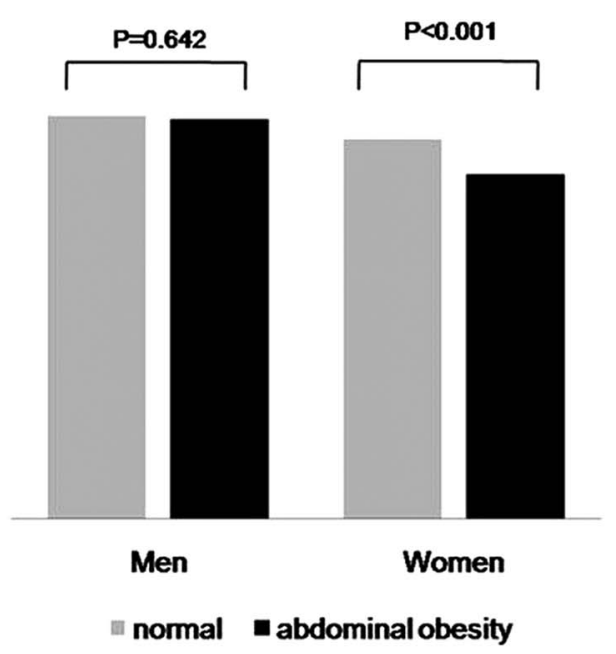

Figure 1 Gender-specific means of EQ-5D according to $B M I(A)$ and WC (B) categories ( $N=13754)$. Mean values of EQ-5D adjusted for age, gender, education, household income, employment, marital status and number of comorbidities $(A)$ and further for BMI (B); BMl was categorised into non-overweight $\left(\mathrm{BMl}<25 \mathrm{~kg} / \mathrm{m}^{2}\right)$, overweight $\left(\mathrm{BMl} \geq 25 \mathrm{~kg} / \mathrm{m}^{2}\right)$ and obesity $\left(\mathrm{BMl} \geq 30 \mathrm{~kg} / \mathrm{m}^{2}\right)$ and WC into normal waist and abdominal obesity (WC $\geq 90 \mathrm{~cm}$ for men and $\geq 85 \mathrm{~cm}$ for women). BMI, body mass index; EQ-5D, EuroQOL-5 Dimensions Scores; WC, waist circumference.

morbidity, usual activities and pain/discomfort in women were more likely to be prevalent for any problem among overweight or obese groups compared with the reference category of non-overweight group (see online supplemental table S2).

\section{Associations between WC categories and EQ-5D scores and gender differences}

Compared with those with normal waists, individuals with abdominal obesity showed significantly lower EQ-5D scores $(\beta=-0.009, p<0.001$; model I of table 4$)$. This significant association remained unchanged even after the effect of BMI was adjusted for in the model $(\beta=-0.009, p=0.002$; model II of table 4). Furthermore, a significant interaction effect between gender and WC categories on EQ-5D was found $(\beta=-0.017, p<0.001$ for women and abdominal obesity; model III of table 4). This finding indicated that women with abdominal obesity had significantly lower EQ-5D scores compared with those with normal waists, but such significance was not apparent for men (model III of table 4; see also figure 1B), even after adjusting for BMI.

In the EQ-5D domains, the prevalence of any problem in all the domains of EQ-5D differed significantly according to WC category, with more prevalence in individuals with abdominal obesity (see online supplemental figure S2). The crude and multivariate associations between WC category and each domain of EQ-5D by gender are shown in online supplemental tables S3 and S4. Women with

Table 3 Association between BMI categories and EQ-5D and its gender difference $(N=13754)$

\begin{tabular}{|c|c|c|c|c|c|c|}
\hline \multirow[t]{2}{*}{ Variables } & \multicolumn{3}{|l|}{ Model I } & \multicolumn{3}{|l|}{ Model II } \\
\hline & Coeff. & (SE) & p Value & Coeff. & (SE) & p Value \\
\hline \multicolumn{7}{|l|}{ BMI categories } \\
\hline Obese & -0.008 & $(0.004)$ & 0.063 & 0.001 & $(0.005)$ & 0.808 \\
\hline Overweight & -0.005 & $(0.002)$ & 0.007 & -0.001 & $(0.002)$ & 0.768 \\
\hline \multicolumn{7}{|l|}{ Gender } \\
\hline Women & -0.016 & $(0.002)$ & $<0.001$ & -0.012 & $(0.002)$ & $<0.001$ \\
\hline \multicolumn{7}{|l|}{ Gender×BMI } \\
\hline Womenxobese & & & & -0.018 & $(0.008)$ & 0.030 \\
\hline Womenxoverweight & & & & -0.011 & $(0.004)$ & 0.002 \\
\hline \multicolumn{7}{|c|}{$\begin{array}{l}\text { Reference group for BMI categories=non-overweight group; reference group for gender=men. } \\
\text { GenderxBMl=interaction effect between gender and BMI. } \\
\text { p Values are from multiple linear regression models. } \\
\text { Model I: adjusted for age, education, income, employment, marital status and number of comorbidities. } \\
\text { Model II: adjusted for model I plus an interaction term between gender and BMI category. } \\
\text { BMI, body mass index; Coeff., regression coefficient; EQ-5D, EuroQOL-5 Dimensions Scores. }\end{array}$} \\
\hline
\end{tabular}


Table 4 Association between WC categories and EQ-5D and its gender difference $(\mathrm{N}=13754)$

\begin{tabular}{|c|c|c|c|c|c|c|c|c|c|}
\hline \multirow[b]{2}{*}{ Variables } & \multicolumn{3}{|l|}{ Model I } & \multicolumn{3}{|l|}{ Model II } & \multicolumn{3}{|c|}{ Model III } \\
\hline & Coeff. & (SE) & p Value & Coeff. & (SE) & p Value & Coeff. & (SE) & p Value \\
\hline \multicolumn{10}{|l|}{ WC categories } \\
\hline Abdominal obesity & -0.009 & $(0.002)$ & $<0.001$ & -0.009 & $(0.003)$ & 0.002 & -0.002 & $(0.004)$ & 0.642 \\
\hline \multicolumn{10}{|l|}{ Gender } \\
\hline Women & -0.016 & $(0.002)$ & $<0.001$ & -0.016 & $(0.002)$ & $<0.001$ & -0.012 & $(0.002)$ & $<0.001$ \\
\hline \multicolumn{10}{|l|}{ BMI categories } \\
\hline Obese & & & & 0.001 & $(0.005)$ & 0.878 & 0.001 & $(0.005)$ & 0.828 \\
\hline Overweight & & & & 0.000 & $(0.002)$ & 0.849 & 0.000 & $(0.002)$ & 0.844 \\
\hline \multicolumn{10}{|l|}{ Gender $\times$ WC } \\
\hline Womenxabdominal obesity & & & & & & & -0.017 & $(0.004)$ & $<0.001$ \\
\hline \multicolumn{10}{|c|}{$\begin{array}{l}\text { Reference group for WC categories=normal waist group; reference group for gender=men. } \\
\text { GenderxWC=interaction effect between gender and WC. } \\
\text { p Values are from multiple linear regression models. } \\
\text { Model I: adjusted for age, education, income, employment, marital status and comorbidities. } \\
\text { Model II: adjusted for model I plus BMI category. } \\
\text { Model III: adjusted for model II plus an interaction term between gender and WC category. }\end{array}$} \\
\hline
\end{tabular}

abdominal obesity were more likely to manifest a problem in the domains of mobility, usual activities, pain/discomfort and anxiety/depression (except for self-care) than those with normal waist (see online supplemental table S4). However, this pattern was not apparent in men.

\section{DISCUSSION}

In this cross-sectional population-based study among the Korean population aged 19-65 years, overall and abdominal obesity were significantly associated with lower EQ-5D scores after adjusting for age and socioeconomic variables such as income, education, marital status and employment, as well as for comorbidities. Noticeably, the association between abdominal obesity and HRQOL remained significant even after controlling for overall obesity. Furthermore, such associations between obesity and HRQOL differed by gender, being significant among women but not among men.

To the best of our knowledge, this significant association between abdominal obesity and HRQOL, after controlling for possible potential confounders and overall obesity, is the first one studied in the general population. In fact, Faulkner et $a l^{24}$ reported such an association among 90 patients with schizophrenia, showing that higher levels of WC were significantly associated with impaired physical quality of life, as measured by SF-12, and its association was independent of BMI levels. Meanwhile, epidemiological cohort studies have demonstrated independent associations of abdominal obesity with the risk for chronic diseases, such as type II diabetes, cardiovascular disease or some cancers such as hepatocellular carcinoma and breast, colon and uterus cancer. $^{12} 2526$ Unlike these chronic diseases, HRQOL reflects a comprehensive health outcome, assessing people's own functional abilities across multiple domains including physical and psychological well-being. For this reason, HRQOL has also been known as a predictor for mortality in older or female population samples. $^{26} 27$

A few studies have reported a stronger association between overall obesity (as measured by BMI) and HRQOL among women than among men. ${ }^{28}$ Unlike the previous studies, our study showed that the statistically significant association of abdominal obesity with HRQOL was apparent among women but not among men. Based on our data (model III in table 4), the coefficient for abdominal obesity in women was approximately 0.02 (the coefficient for the WC variable $(-0.002)+$ the coefficient for an interaction term of women $\times$ abdominal obesity $(-0.017))$, indicating a variation in EQ-5D scores between women with and without abdominal obesity in the fully adjusted model (even further after the adjustment for BMI). In other words, EQ-5D levels were impaired by $2 \%$ in women with abdominal obesity compared with those with normal waists. The magnitude of variation in the present study merits discussion of whether this is clinically meaningful. A few studies have investigated the smallest change in EQ-5D score that can be regarded as clinically meaningful, that is, the minimal clinically important difference (MCID). ${ }^{20} 2930$ The mean MCID of EQ-5D was 0.04-0.07 across a range of conditions (eg, post-traumatic stress disorder, rheumatoid arthritis, limb reconstruction, osteoarthritis or chronic obstructive disease). The mean MCIDs were all obtained from patient groups, and none of these studies focused specifically on obesity within the general population. Nevertheless, we speculate that the mean MCID for abdominal obesity in the present study may have a lower value than the minimum MCIDs previously reported for various patient groups. Furthermore, no previous studies have reported coefficients for the association between abdominal obesity and HRQOL in a fully adjusted model, where BMI was even adjusted. In this respect, the statistically 
significant $2 \%$ decrease of EQ-5D in women with abdominal obesity among the general population may also be clinically meaningful.

The gender difference in the association between abdominal obesity and HRQOL cannot be fully investigated in the present study, but could be explained by two potential conjectures. First, this may be related to biophysical problems resulting from abdominal obesity among women. Women usually report worse health than men, which may be a result of sleepiness and fatigue. ${ }^{31}$ In fact, sleepiness and fatigue are major symptomatic consequences of abdominal obesity associated with insulin resistance, which is an underlying mechanism for the development of abdominal obesity. ${ }^{32}$ Moreover, women report worse pain than men, as Unruh $^{13}$ argued that women were more likely to report greater frequency, severity and duration of pain than do men, and moreover, to respond to pain more than do men, especially due to obesity. Stone and Broderick $^{14}$ showed that overweight and obese individuals reported more daily pain than non-overweight individuals, and the obesity-pain association was stronger for women than for men.

The gender differences in the associations between overall or abdominal obesities and HRQOL may further be explained within the psychological and sociocultural context of women's lives. The impact of obesity on psychological well-being may not be comparable between women and men. ${ }^{33}$ Obese women could be more likely than their male counterparts to experience poor psychological well-being such as body dissatisfaction, low selfesteem and depression, ${ }^{33}$ which may be more prominent in Korea than other countries in light of the Korean cultural background. Today's society values thinness for women's bodies and exerts an intense pressure on women to engage in appearance monitoring and surveillance for their attractiveness, mostly projecting attributes such as health. ${ }^{34} 35$ Since the 2000s, dieting, body contouring and plastic surgeries have been actively introduced among women in Korean society, with an increasing demand for well-being and good health. According to the results of one survey, $99 \%$ of Korean women were not fully satisfied with their own bodies and $53 \%$ considered having either cosmetic or plastic surgery. ${ }^{36}$ It was also argued that women's sense of worth is considerably determined by their appearance, and as a result, women are more limited in exercising their power and abilities, by means other than appearance, in Korean society than in other societies. ${ }^{37}$ This may, in part, be ingrained in the Korean patriarchal culture permeated by Confucian family norms and traditions. Women in Korean society are more likely to internalise men's views of their own bodies more than women in other societies. ${ }^{38}$ In this sociocultural context, overweight and obese women may consider themselves a marginalised group from thin or non-overweight women in the dynamics of health and practice. Thus, such conditioning may increase body dissatisfaction, ${ }^{35}$ which may in turn result in depressive symptoms among overweight and obese women. ${ }^{39}$

Our study has several strengths. This is the first study to elucidate the association between abdominal obesity and HRQOL in the general population. Moreover, this study distinguishes itself from previous studies in the adjustment for all the potential confounding factors (ie, age, household income, education, employment, marital status and comorbidities) to be identified in the association between obesity and HRQOL. Nevertheless, our study also has some limitations. Because the measurement of abdominal obesity in the KNHANES has been confined to WC, advanced or modified indices beyond WC (ie, imaging techniques measured by CT and MRI, waist-to-hip ratio, waist-to-height ratio or sagittal abdominal diameter) could not be addressed in this study. ${ }^{40} 41$ Thus, although WC was found to be an adequate index of abdominal adiposity to assess a large population, other abdominal adiposity indices may need to be included to investigate the association with HRQOL. Furthermore, our study results may not guarantee a causal relationship between abdominal obesity and HRQOL, due to the nature of a cross-sectional study design, and also might not be generalisable to other cultural population groups.

\section{CONCLUSIONS}

Abdominal obesity was significantly associated with lower HRQOL in general Korean population, which was independent of overall obesity. This association differed by gender, being significant especially among women but not among men. Therefore, abdominal obesity, as measured by WC, needs to be assessed in order to monitor and evaluate HRQOL in caring for populations in preventing and reducing obesity. In particular, primary healthcare professionals should pay more attention to gender differences in the impacts of obesity on HRQOL when evaluating population-based health programmes.

Author affiliations

${ }^{1}$ College of Nursing, Korea University, Seoul, South Korea

${ }^{2}$ Medical Division, Green Cross Corp, Yongin, South Korea

${ }^{3}$ Department of Biostatistics, College of Medicine, Korea University, Seoul, South Korea

Contributors JC developed the hypothesis of this study and prepared the manuscript draft. $\mathrm{JL}$ and $\mathrm{SJ}$ were involved in data collection and analysis and provided expert consultation on data interpretation. All authors were involved in the review and revision of the manuscript and gave final approval of the manuscript.

Funding This research was supported by the Basic Science Research Program through the National Research Foundation of Korea (NRF), funded by the Ministry of Education, Science and Technology (No. 2010-0022022).

Competing interests None.

Ethics approval The Institutional Review Board at Korea University.

Provenance and peer review Not commissioned; externally peer reviewed.

Data sharing statement No additional data are available. 
Open Access This is an Open Access article distributed in accordance with the Creative Commons Attribution Non Commercial (CC BY-NC 3.0) license, which permits others to distribute, remix, adapt, build upon this work noncommercially, and license their derivative works on different terms, provided the original work is properly cited and the use is non-commercial. See: http:// creativecommons.org/licenses/by-nc/3.0/

\section{REFERENCES}

1. World Health Organization. Global health risks: mortality and burden of disease attributable to selected major risks. Geneva, Switzerland: WHO press, World Health Organization, 2009.

2. Ministry of Health \& Welfare and Korea Center for Disease Control \& Prevention. 2009 Korea National Health and Nutrition Examination Survey. Korea National Health and Nutrition Examination Survey: Ministry of Health \& Welfare and Korea Center for Disease Control \& Prevention, 2011

3. Cassano PA, Rosner B, Vokonas PS, et al. Obesity and body fat distribution in relation to the incidence of non-insulin-dependent diabetes mellitus. A prospective cohort study of men in the normative aging study. Am J Epidemiol 1992;136:1474-86.

4. Willett WC, Manson JE, Stampfer MJ, et al. Weight, weight change, and coronary heart disease in women. Risk within the 'normal' weight range. JAMA 1995;273:461-5.

5. Jia $\mathrm{H}$, Lubetkin El. The impact of obesity on health-related quality-of-life in the general adult US population. $J$ Public Health (Oxf) 2005;27:156-64.

6. Soltoft $F$, Hammer M, Kragh $\mathrm{N}$. The association of body mass index and health-related quality of life in the general population: data from the 2003 Health Survey of England. Qual Life Res 2009;18:1293-9.

7. Serrano-Aguilar P, Munoz-Navarro SR, Ramallo-Farina Y, et al. Obesity and health related quality of life in the general adult population of the Canary Islands. Qual Life Res 2009;18:171-7.

8. Mond JM, Baune BT. Overweight, medical comorbidity and health-related quality of life in a community sample of women and men. Obesity (Silver Spring) 2009;17:1627-34.

9. Huang IC, Frangakis C, Wu AW. The relationship of excess body weight and health-related quality of life: evidence from a population study in Taiwan. Int J Obes (Lond) 2006:30:1250-9.

10. Rexrode KM, Carey VJ, Hennekens $\mathrm{CH}$, et al. Abdominal adiposity and coronary heart disease in women. JAMA 1998;280:1843-8.

11. Zhang $\mathrm{C}$, Rexrode KM, van Dam RM, et al. Abdominal obesity and the risk of all-cause, cardiovascular, and cancer mortality: sixteen years of follow-up in US women. Circulation 2008;117:1658-67.

12. de Koning L, Merchant AT, Pogue J, et al. Waist circumference and waist-to-hip ratio as predictors of cardiovascular events: meta-regression analysis of prospective studies. Eur Heart J 2007;28:850-6.

13. Unruh AM. Gender variations in clinical pain experience. Pain 1996;65:123-67.

14. Stone AA, Broderick JE. Obesity and pain are associated in the United States. Obesity (Silver Spring) 2012;20:1491-5.

15. Muennig $\mathrm{P}$, Lubetkin $\mathrm{E}$, Jia $\mathrm{H}$, et al. Gender and the burden of disease attributable to obesity. Am J Public Health 2006;96:1662-8.

16. Korea Centers for Disease Control and Prevention. The Fourth Korea National Health and Nutrition Examination Survey (KNHANES IV-3).

Seoul: Korea Centers for Disease Control and Prevention, 2009.

17. Multi-year averages from a rolling sample survey. The Survey Research Methods Section, 2000.

18. Sekikawa A, Kuller LH, Ueshima $\mathrm{H}$, et al. Coronary heart disease mortality trends in men in the post World War II birth cohorts aged 35-44 in Japan, South Korea and Taiwan compared with the United States. Int J Epidemiol 1999;28:1044-9.

19. The Euroqol Group. Euroqol-a new facility for the measurement of health-related quality-of-life. Health Policy 1990;16:199-207.

20. Minet Kinge J, Morris S. Socioeconomic variation in the impact of obesity on health-related quality of life. Soc Sci Med 2010;71:1864-71.
21. Nam HS. South Korean time trade-off values for EQ-5D health states. Korea Centers for Disease Control and Prevention, 2007. $\mathrm{http}: / / \mathrm{www} . \mathrm{cdc} . \mathrm{go} . \mathrm{kr} / \mathrm{CDC} / \mathrm{cms} /$ content/49/12449 view.html

22. World Health Organization. Global database on body mass index: $\mathrm{BMI}$ classification. Secondary Global database on body mass index: BMI classification, 2008. http://www.who.int/bmi/index.jsp? introPage=intro_3.html

23. Lee SY, Park HS, Kim DJ, et al. Appropriate waist circumference cutoff points for central obesity in Korean adults. Diabetes Res Clin Pract 2007;75:72-80.

24. Faulkner G, Cohn T, Remington G, et al. Body mass index, waist circumference and quality of life in individuals with schizophrenia Schizophr Res 2007;90:174-8.

25. Schlesinger S, Aleksandrova K, Pischon T, et al. Abdominal obesity, weight gain during adulthood and risk of liver and biliary tract cancer in a European cohort. Int J Cancer 2013;132:645-57.

26. Folsom AR, Kushi LH, Anderson KE, et al. Associations of general and abdominal obesity with multiple health outcomes in older women: the lowa Women's Health Study. Arch Intern Med 2000;160:2117-28.

27. Kroenke $\mathrm{CH}$, Kubzansky LD, Adler $\mathrm{N}$, et al. Prospective change in health-related quality of life and subsequent mortality among middle-aged and older women. Am J Public Health 2008;98:2085-91

28. Vasiljevic N, Ralevic S, Marinkovic J, et al. The assessment of health-related quality of life in relation to the body mass index value in the urban population of Belgrade. Health Qual Life Outcomes 2008;6:106.

29. Le QA, Doctor JN, Zoellner LA, et al. Minimal clinically important differences for the EQ-5D and QWB-SA in Post-traumatic Stress Disorder (PTSD): results from a Doubly Randomized Preference Trial (DRPT). Health Qual Life Outcomes 2013;11:59.

30. Walters SJ, Brazier JE. Comparison of the minimally important difference for two health state utility measures: EQ-5D and SF-6D. Qual Life Res 2005;14:1523-32.

31. Chun H. Gender as a social determinant of health: a Korean perspective. Seoul National University, 2006.

32. Vgontzas AN, Bixler EO, Chrousos GP. Obesity-related sleepiness and fatigue: the role of the stress system and cytokines. Ann N Y Acad Sci 2006;1083:329-44.

33. Bentley TG, Palta M, Paulsen AJ, et al. Race and gender associations between obesity and nine health-related quality-of-life measures. Qual Life Res 2011;20:665-74.

34. Thogersen-Ntoumani C, Ntoumanis N, Cumming J, et al. Can self-esteem protect against the deleterious consequences of self-objectification for mood and body satisfaction in physically active female university students? J Sport Exerc Psychol 2011;33:289-307.

35. Paquette MC, Raine K. Sociocultural context of women's body image. Soc Sci Med 2004;59:1047-58.

36. Jeong JC. Critiques of the arguments on Korean women's body. $J$ Commun Sci 2007;7:292-318.

37. Im IS. Body contouring project in a Korean society: focusing on the expansion of cosmetics industries. Korean J Sociol 2002;36: 183-204.

38. Han SA. Feminist study on women's practices to have slender, beautiful bodies: with a focus on the 'diet' experiences Ewha Woman's University, 1997.

39. Pastore LM, Patrie JT, Morris WL, et al. Depression symptoms and body dissatisfaction association among polycystic ovary syndrome women. J Psychosom Res 2011;71:270-6.

40. Carlsson AC, Riserus U, Engstrom G, et al. Novel and established anthropometric measures and the prediction of incident cardiovascular disease: a cohort study. Int $J$ Obes (Lond) 2013:37:1579-85.

41. Shuster A, Patlas M, Pinthus $\mathrm{JH}$, et al. The clinical importance of visceral adiposity: a critical review of methods for visceral adipose tissue analysis. Br J Radiol 2012;85:1-10. 